\title{
HEAD INJURY-A NEGLECTED PUBLIC HEALTH PROBLEM: A FOUR-MONTH PROSPECTIVE STUDY AT JIMMA UNIVERSITY SPECIALIZED HOSPITAL, ETHIOPIA
}

\author{
Isabel Aenderl ${ }^{1}$, Teshager Gashaw $^{2}$, Matthias Siebeck $^{1,3}$, Wolf Mutschler $^{1}$
}

ABSTRACT

BACKGROUND: Trauma, especially head trauma, is an expanding major public health problem and the leading cause of death of the young and productive part of the world's population. Research is mainly done in high-income countries where only a small proportion of the worldwide fatalities occur. The intention of this study was to analyze head injury in a setting where most patients in low-and middleincome countries receive treatment, a referral hospital with general but no neurosurgical service like Jimma University Specialized Hospital. The study aims to provide surgeons, hospital managers and health planners working in similar set-ups with baseline information for further investigation and prevention programs intending to reduce the burden of head injury.

METHODS: All head injury patients presented to Jimma University Specialized Hospital between March and June 2010 were included in this prospective research. Epidemiological, clinical and management data were collected for the study.

RESULTS: Out of 52 patients, 47 were males. The median age was 20.0 years $(S D=13.3)$. Fights $(n=20$, $38.5 \%)$ and road traffic accidents $(n=19,36.5 \%)$ were the most common causes of head injury. Half of the patients sustained mild and 36.5\% sustained severe head injury. The initial GCS had a significant correlation with the outcome. The mortality rate was $21.2 \%$. Of all patients $76.9 \%$ were managed conservatively.

CONCLUSION: Prevention of road traffic accidents and improvement of conservative care were identified as major methods to reduce the burden of head injury in a set-up similar to Jimma. Further studies on head injury patients in low-income countries should be done.

KEYWORDS: Head injury, Traffic accidents, Violence, Low

DOI: http://dx.doi.org/10.4314/ejhs.v24i1.4

\section{INTRODUCTION}

For ages, communicable diseases were the major cause of death in the whole world. This changed through industrialization and medical progress. In high-income countries, where $15 \%$ of the earth's population lives, chronic diseases are responsible for most deaths of people older than 44 years. When it comes to the young and productive part of the population aged 15 to 44 , injury is the leading cause of death (1). In 2002, injury accounted for
5.2 million deaths in the world with $90 \%$ happening in low-and middle-income countries. Globally, $9 \%$ of all deaths are caused by injury. More people die each year of injury compared with the cumulative amount of deaths due to HIV/AIDS and malaria $(2,3)$. Africa carries the highest burden of disability and premature deaths secondary to injury (4). Especially, road traffic accidents will rise with economic growth and motorization in Africa but there are only a few politicians, health planners and donors who focus

\footnotetext{
${ }^{1}$ Department of Surgery, Ludwig Maximilian University, Munich, Germany

${ }^{2}$ Department of Surgery, College of Public Health and Medical Science, Jimma University, Ethiopia

${ }^{3}$ Center for International Health, Ludwig Maximilian University, Munich, Germany

Corresponding Author: Isabel Aenderl, Email: isabelaenderl@yahoo.de
} 
on that $(5,6)$. It can be assumed that there will be a transition similar to high income countries from communicable diseases to non-communicable diseases. By the year 2020, road traffic accident is expected to be the sixth cause of death worldwide and traffic injury will be the second most prominent cause of disability-adjusted life years (DALYs) lost in low- and middle-income countries (5). Concerning road traffic accidents in Ethiopia, the situation is already alarming. The country has one of the highest number of fatalities per vehicle worldwide (7) and there is only one physician per 30000 inhabitants (8). Regarding the leading cause of trauma deaths, many studies identified head injury besides multiple trauma in countries all over the world $(2,9,10,11,12)$.

Head injury patients in low-income countries need to overcome barriers to receive medical treatment in a general surgery unit (13). Transport is often costly, long and difficult to organize. Patients seldom receive prehospital medical care on the transport because rescue systems are not well established. This can aggravate secondary brain injury due to hypoxia and hypotension. Even if they reach medical professionals, it is most likely a nurse or a general practitioner in a rural health center. General surgery is mainly available in bigger cities and neurosurgery and CT scan are accessible only in the capital cities. In hospitals, management of severe head injury suffers often from shortage of oxygen and ventilators. Head injury patients discharged with sequels have seldom access to rehabilitation facilities.

Even though head injury is a major public health problem worldwide, most research and studies are conducted in the setting of highincome countries where only a small proportion of fatalities occur $(2,20)$. The intention of this study is to analyze epidemiology, management and outcome in a setting where most head injury patients in low- and middle-income countries receive treatment, a referral hospital with general but no neurosurgical service like Jimma University Specialized Hospital. The study aims to provide surgeons, hospital managers and health planners working in similar set-ups with baseline information for further investigation, prevention programs and guideline development intending to reduce the burden of head injury. Specific questions were raised to determine age and sex distribution, distance and time to reach the hospital, causes, initial severity of injury related to outcome, length of hospital stay, performed surgical procedures and sequels of head injury patients in Jimma University Hospital.

\section{MATERIALS AND METHODS}

Jimma University Specialized Hospital is a teaching hospital in Southwest Ethiopia. The hospital is a referral hospital for around 15 million people. The surgical department has 120 beds, two ICU beds, three operation rooms and one outpatient department. A neurosurgeon and a CT scan are not yet available. In the monthly mortality meeting of the surgical department held in Jimma, it was reported that head injury was frequently identified as leading cause of death.

The study was designed as a four-month prospective, observational study carried out from March to June 2010 at Jimma University Specialized Hospital. All head injury patients who arrived during the study period at the surgical outpatient department were included. Head injury was defined as any kind of injury to the head with loss of consciousness and/or deep laceration on the head and/or positive history of head trauma reported by the patient or accident witness.

Main data was collected at first presentation of the patient at the outpatient department and at time of discharge. During the hospital stay, patients were followed up with a neurological observation chart. Special events like surgical interventions and problems with the clinical workflow were recorded. Epidemiological data was collected with the help of nurses, students and residents who were able to translate from local languages to English. Clinical data was assessed through examination and observation by the medical professionals in charge of the patient before they were filled into the questionnaire. The program $\mathrm{R}$ was used for analyzing the data.

Ethical clearance was obtained from the Ethical Review Board of Jimma University. All collected data were kept confidential and used for the study purpose only. Patients did not enter the research without informed consent. For patients under the age of 15 , consent was given by the parents or adults in charge. Patients who were unconscious upon admission were informed about the study and their right to be excluded as soon as they regained consciousness. 


\section{RESULTS}

Epidemiological data: In total, 52 head injury patients were included in the study. The median age was 20 years $(\mathrm{SD}=13.3)$ with a range from 3 to 65 (Table 1). The female/male ratio was 1:9. Interpersonal fight $(\mathrm{n}=20,38.5 \%)$ and traffic accidents $(n=19,36.5 \%)$ accounted for most of the injuries. Of all injuries, $15.4 \%(n=8)$ were due to falling accidents mainly in children while playing on trees, collecting fruits or firewood. The fights were mainly about farming land. Thirteen of 19 traffic accidents were pedestrians that were hit by a motorized vehicle. Other less frequent occasions were passengers who felt from trucks $(n=3)$, injured passengers of a car $(\mathrm{n}=2)$ or motorcyclists $(\mathrm{n}=1)$. The median distance to the hospital was $28.5 \mathrm{~km}$. The median rescuing speed was 7.50 $\mathrm{km} / \mathrm{h}$.

Table 1: Age in years, sex and severity of injury related to the outcome of all patients

\begin{tabular}{lccc}
\hline \multirow{2}{*}{ Variable } & \multicolumn{2}{c}{ Outcome } & \\
\hline Age & Survived (\%) & Died (\%) & Total (\%) \\
$<15$ & $17(100)$ & 0 & $17(33)$ \\
$15-24$ & $11(65)$ & $6(35)$ & $17(33)$ \\
$25-34$ & $6(67)$ & $3(33)$ & $9(17)$ \\
$35-44$ & $3(75)$ & $1(25)$ & $4(8)$ \\
$>44$ & $4(80)$ & $1(20)$ & $5(10)$ \\
\hline Sex & & & \\
Male & $37(79)$ & $10(21)$ & $47(90)$ \\
Female & $4(80)$ & $1(20)$ & $5(10)$ \\
\hline Severity of injury (initial GCS) & & & \\
Mild (GCS initial 13-15) & $26(100)$ & 0 & $7(14)$ \\
Moderate (GCS initial 9-12) & $7(100)$ & 0 & $6(12)$ \\
Severe & & & $7(13)$ \\
$\quad$ GCS initial 7-8 & $6(100)$ & 0 & $6(12)$ \\
$\quad$ GCS initial 5-6 & $1(14)$ & $6(86)$ & \\
$\quad$ GCS initial 3-4 & $1(17)$ & $5(83)$ & \\
\hline
\end{tabular}

Clinical data: The distribution of the severity of injury measured with the initial Glasgow Coma Score (GCS) is shown in Table 1. Seventy-one percent of all patients were discharged with a good recovery (Glasgow Outcome Scale [GOS] 5), $7.7 \%$ with a disability and $21.2 \%$ died (GOS 1 ). The initial GCS and the GOS of all patients had a significant correlation (rho $=0.8 ; \mathrm{p}<0.001$; Spearman's rank correlation). All patients with initial GCS greater than 6 survived. All patients with initial GCS 6 and less died except two children (Table 1). Patients with both non-reactive pupils at the initial examination died in $87.5 \%$ of the cases. Patients who sustained injury from fight or fall were more likely to have an outcome with good recovery (GOS 5) compared to patients with road traffic injury (RTI) or other causes. Only $10 \%$ of the patients who sustained injury from interpersonal fight had an initial GCS below 9 compared to $52.6 \%$ in RTI patients $(\mathrm{p}=0.01$; test of equality of proportions with continuity correction). Median time for all patients to reach the hospital after injury was 3.75 hours. Almost half of the patients with severe head injury arrived within the first two hours after the accidents. Their survival rate was $33.3 \%$ compared to $50.0 \%$ survivals in the group that arrived later. The mean initial GCS in the early group was five points compared to 5.7 in the late group. The median time in hospital of the admitted patients $(55.8 \%)$ was eight days. Out of all patients who died, $54.5 \%$ died in the first 48 hours of the hospital stay. Secondary diagnosis and sequels at discharge of all patients are shown in Table 2 . 
Table 2: Secondary diagnosis and sequels of all patients at discharge

\begin{tabular}{|l|c|c|}
\hline Further injuries & Numberof patients & Percent \\
\hline Secondary diagnosis & & \\
Fracture (not skull) & 8 & 15 \\
Aspiration pneumonia & 3 & 12 \\
Injury to the eye & 1 & 6 \\
Spinal injury & 1 & 2 \\
Haemato-pneumothorax & & 2 \\
\hline Sequels at discharge & 3 & 8 \\
Limb weakness & & 6 \\
Posttraumatic stress & 2 & 4 \\
syndrome & 1 & 2 \\
Aphasia & 3 & \\
Balance disorder & & \\
\hline
\end{tabular}

Management data: Seventy-seven percent of all patients were managed conservatively. Two burrhole procedures for suspected haematoma were done. One patient with subdural haematoma died and one with epidural survived. Four patients were operated on depressed skull fractures. One of them died, and in one patient, an underlying epidural haematoma was evacuated. Other procedures were two chest tube insertions, one external fixation of a femoral fracture and one ligation of a superficial temporal artery due to continuous bleeding. In two patients, tracheotomies were performed. Six patients had a primarily visible or emergencyexplored skull fracture. Twenty-seven patients had a skull x-ray which showed a fracture in 15 cases. Nineteen patients had no skull x-ray done. Median initial GCS of the patients that had visible skull fractures on the x-rays was 13. Patients who underwent no skull x-ray had a median initial GCS of 10 .

\section{DISCUSSION}

The study identified the young male part of the population as a major group sustaining head injury. This corresponds to various studies on trauma or head trauma in Africa [15, 18, 21, 22, 23, 24]. Agrawal et al. suggested that this is because females, elderly people and children rather staying in the house and therefore getting less exposure to risk factors leading to injury [25]. The injury or death of young male members of the

population causes social and economic difficulties because they are often the breadwinners of the whole family. Jimma University Hospital is a referral hospital for around 15 million people living in the Southwest of Ethiopia. But, the median distance from place of injury to hospital was $28.5 \mathrm{~km}$. Therefore, it can be assumed that many patients from far and remote places do not reach the hospital. The low rescuing speed of 7.5 $\mathrm{km} / \mathrm{h}$ is due to lack of infrastructure and rescue service. Patients arrived by rented public minibuses, carried on a stretcher by attendants or on foot.

Fifty percent of all the head injury patients presented in the outpatient department with mild head injury in comparison to about $80 \%$ to $90 \%$ in high-income countries $(14,26)$. The threshold for mild head injury patients seeking care in Ethiopia is high. They fear the cost of transport and of treatment and they might be less aware of lifethreatening complications. Another reason for the low percentage of this group is their frequent habit of early self-discharge before proper records are taken. The overall mortality rate of $21.2 \%$ and the mortality rate of $57.9 \%$ in severe head injuries are similar to other studies conducted in Nigeria, Kenya, Benin and India $(18,19,21,23,25)$. Initial GCS and pupilary reaction have been identified as valid outcome predictors in this study like in many other studies $(17,18)$. These outcome predictors 
are very useful when it comes to difficult decisions in the everyday work of a doctor in a similar set-up. In Jimma University Specialized Hospital, for example, there are six beds on ICU for all departments. Only $2 / 3$ of all severe head injury patients were admitted to ICU. The patients with best chances to recover should profit from the limited resources to ensure effective allocation. This is only possible with knowing indicators to predict outcome (27). An exception should be made for children. All the eleven patients who died were older than 13 and had an initial GCS < 7. The two children with initial GCS $<7$ survived.

The two major causes of injury were interpersonal fight $(38.5 \%)$ and road traffic accidents (36.5\%). Interpersonal fight was also identified as a major cause in a head trauma study carried out in South Africa (41\%) (15), and in a trauma study from Ethiopia (32.2\%) (22). Ayana et al. conducted a research on trauma in the same region of Ethiopia. They recommend teaching of de-escalation skills as a cheap method to prevent injury in the region. This research can confirm the recommendation of Ayana et al. with restriction. Ayana et al. did not consider the outcome of their patients. In this research, patients who sustained head injury from road traffic accidents had a significantly lower initial GCS and more often a fatal outcome compared to patients who sustained head injury from interpersonal fight. Road traffic accidents were the major cause of head injury in a study from Nigeria $(69 \%)$ (21) and of trauma in Tanzania (43.9\%) (24), Nigeria (62.4\%) (12) and trauma deaths in Uganda (46\%) (9). Thus, it appears that the focus on trauma prevention in countries like Ethiopia should mainly be on road traffic accidents. An interdisciplinary action embracing legislation and law enforcement, road users and road planners is mandated to work on prevention of road traffic accidents. Injury prevention is based on education, enforcement and engineering (28). Useful examples for the Ethiopian settings would be road safety education for children in school, enforcement of speed limits and helmet use and compulsory construction of pavements, overhead crossings and traffic lights. In Ethiopia, it is not only alcohol which is a cause of driver impairment-Khat, a natural amphetamine-like substance in leaves, is chewed in many regions of the country for social reasons and especially by drivers to stay awake (29).
The median time for the patients to reach the hospital was 3.75 hours. A similar median time of 4 hours was recorded in an epidemiological study of 1231 trauma patients in Jimma University Hospital in 2004 (30). This is due to distance from place of injury to hospital and rescuing speed. During the pre-hospital time most of the patients in this study, unlike in high-income countries, stayed without any attendance by a health professional. This long period where secondary brain injury and further complication e.g. aspiration are likely to occur worsens the condition of the patient. A rescuing system with pre-hospital medical care should mark a milestone for the politicians working on the development of the Ethiopian health system. Even if a rescuing system is expensive and difficult to implement it plays a decisive role in reducing mortality and morbidity of trauma (31). Almost half of the patients with severe head injury arrived within the first two hours after accident. Their survival rate and initial GCS was less than in the group that arrived later. It can be assumed that some of the very severely injured patients had died on their long way before reaching the hospital. This goes along with the result that indicated that only a minority of patients came from a distance of more than $50 \mathrm{~km}$.

Fractures other than skull fractures were identified as the most common further injury in this and other studies from Kenya (18) and India (25). For example, a motor impairment of a limb caused by an inadequately treated fracture can lead to a disability and reduction of workforce affecting a whole family. Thus, treatment of associated fractures is a relevant part of management of head injury patients. Aspiration pneumonia was another frequent problem aggravated through long time of transport to the hospital and a shortage of ICU beds leaving 1/3 of all patients with severe head injury in the normal ward without intubation. Early antibiotic treatment is essential when aspiration pneumonia is suspected. Five out of eight patients who survived severe head injury were discharged with sequels such as limb weakness, posttraumatic stress syndrome and aphasia. This shows that further treatment after discharge is needed. Outcome improvement of severe head injury patients is not only about enhancing acute care but providing rehabilitation facilities (19). 
Seventy-seven percent of all the patients were managed conservatively. One reason for this high percentage is that $50.0 \%$ of all the patients sustained mild head injury with less likelihood of requiring surgical intervention. Another reason might be the absence of a CT scan in the hospital with the consequence that management decisions are solely based on clinical presentation of the patient. This could lead to an under-diagnosis of possible surgically treatable secondary brain injuries like intracranial haematomas. Blood for a possible intraoperative transfusion needs to be prepared prior to an operation. Postoperative facilities, especially the number of ventilators, are limited. The patients can profit from standard conservative and surgical procedures that can be safely performed in set-ups like Jimma. Teaching nurses and doctors how to perform neurological observation and coma care, teaching general surgeons about burr hole procedures, and a fixed implementation with a guideline could improve care (15).

More than $1 / 3$ of all the patients had no skull x-ray taken. Their median initial GCS was 10 . Many severely injured patients directly went to the ICU or to the operation room without an $\mathrm{x}$-ray taken to ensure immediate intubation and ventilation. In some patients with GCS of 15 and without any risk factors, the physician in charge did not order a skull x-ray. In more than half of the patients undergoing skull $\mathrm{x}$-ray, a fracture could be found and their median initial GCS was less than in patients without diagnosed skull fracture. The skull $\mathrm{x}$-ray is a method to diagnose a skull fracture which is a risk factor for developing complication. However, it is a limited resource, and some patients cannot pay or refuse to pay for it. Ohaegbulam et al. found out that in their research on CT scan findings in head injury patients in a hospital in Nigeria the frequent use of CT scan reduced mortality (16). A CT scan in their set-up costs about 300 USD, and is affordable for most of the patients only with the financial support of family and friends. A CT scan is planned to be established in Jimma. This will surely improve the management of head injury patients even though financing and maintenance will be a challenge.

A major limitation of the study is the short study period of four months. The sample size of 52 patients makes it difficult to generalize the conclusions. Some patients, especially mild head injury patients, may have stayed in the outpatient department only for a short time without proper documentation taken due to self-discharge. These patients were not included in the research. Some other patients were excluded because the records were incomplete or invalid. Translation from different local languages to English for obtaining epidemiological data may have also distorted the epidemiological results.

\section{ACKNOWLEDGEMENTS}

We would like to thank Prof. Kanz and Dr. Samson Esseye for their support. Special thanks go to the staff of the department of surgery and of the intensive care unit at Jimma University Specialized Hospital for their help to collect the data and for their dedication managing the patients. Sincere thanks are given to German Academic Exchange Service (DAAD) for the financial support. This publication is part of the doctoral thesis of Isabel Aenderl at the medical faculty of Ludwig Maximilian University Munich.

\section{REFERENCES}

1. Krug EG, Sharma GK, Lozano R. The global burden of injuries. Am J Public Health, 2000;90(4):523-6.

2. Hofman K, Primack A, Keusch G, Hrynkow $\mathrm{S}$. Addressing the growing burden of trauma and injury in low- and middle- income countries. Am J Public Health, 2005;95(1):13.

3. WHO, The World Health Report 2004: Changing History, 2004: Geneva.

4. WHO, The World Health Report 1999: Making a Difference, 1999: Geneva.

5. Lindstrand A, Bergström $\mathrm{S}$, Rosling $\mathrm{H}$, Rubenson B, Tylleskär T. Global Health -an introductory textbook. 2006: Studentlitteratur. 326.

6. WHO, The global burden of disease: 2004 update, 2008: Geneva.

7. WHO. Road safety status Ethiopia. 2008 [cited 2013 05/21]; Available from: http://www.who.int/violence_injury_preventio n/road_safety_status/country_profiles/ ethiopia.pdf. 
8. WHO. Ethiopia health profile. 2013 [cited 2013 05/21]; Available from: http://www.who.int/gho/countries/eth.pdf.

9. Jayaraman S, Ozgediz D, Miyamoto J, Caldwell N, Lipnick MS, Mijumbi C, Mabweijano J, Hsia R, Dicker R. Disparities in injury mortality between Uganda and the United States: comparative analysis of a neglected disease. World J Surg, 2011;35(3):505-11.

10. Thanni LO, Kehinde OA. Trauma at a Nigerian teaching hospital: pattern and documentation of presentation. Afr Health Sci, 2006;6(2):104-7.

11. Jennett B. Epidemiology of head injury. Arch Dis Child, 1998;78(5):403-6.

12. Solagberu BA, Adekanye AO, Ofoegbu CP, Udoffa US, Abdur-Rahman LO, Taiwo JO. Epidemiology of trauma deaths. WestAfr $J$ Med, 2003;22(2):177-81.

13. Mock CN, nii-Amon-Kotei D, Maier RV. Low utilization of formal medical services by injured persons in a developing nation: health service data underestimate the importance of trauma. J Trauma, 1997;42(3):504-13.

14. Zock ML, Leidel BA, Biberthaler $P$, Mutschler W, Kanz KG. Notfalldiagnostik bei leichtem Schädel-Hirn-Trauma. Notfall Rettungsmedizin, 2011;2011(4):261-7.

15. Alexander T, Fuller G, Hargovan P, Clarke DL, Muckart DJ, Thomson SR. An audit of the quality of care of traumatic brain injury at a busy regional hospital in South Africa. $S$ Afr J Surg, 2009;47(4):120-2, 124-6.

16. Ohaegbulam SC, Mezue WC, Ndubuisi CA, Erechukwu UA, Ani CO. Cranial computed tomography scan findings in head trauma patients in Enugu, Nigeria. Surg Neurol Int, 2011;2:182.

17. Perel P, Edwards P, Wentz R, Roberts I. Systematic review of prognostic models in traumatic brain injury. BMC Med Inform DecisMak, 2006;6:38.

18. Mwang'ombe NJ, Kiboi J. Factors influencing the outcome of severe head injury at Kenyatta National Hospital. East Afr Med J, 2001; 78(5):238-41.

19. Agrawal D, Joshua SP, Gupta D, Sinha S, Satyarthee GD. Can glasgow score at discharge represent final outcome in severe head injury? J Emerg Trauma Shock, 2012; 5(3):217-9.

20. Schmucker U, Seifert J, Stengel D, Matthes G, Ottersbach C, Ekkernkamp A. [Road traffic crashes in developing countries]. Unfallchirurg, 2010; 113(5):373-7.

21. Emejulu JK. Epidemiological patterns of head injury in a newly established neurosurgical service: one-year prospective study. Afr J Med MedSci, 2008;37(4): 383-8.

22. Ayana B, Mekonen B, Lollino N. The 'hit by a stick' disease: an epidemiologic study of the causes of trauma in a non-profit hospital in rural Ethiopia. Trop Doct, 2012;42(1):1-4.

23. Fatigba OH, Mensah E, Salako AA, Babio R, Mensa Savi De Tove K, Gandaho P. [Clinical and radio-anatomical aspects of traumatic brain injuries after road crash at one hospital, Benin]. Tunis Med, 2011;89(11):837-40.

24. Casey ER, Muro F, Thielman NM, Maya E, Ossmann EW, Hocker MB, Gerardo CJ. Analysis of traumatic injuries presenting to a referral hospital emergency department in Moshi, Tanzania. Int $J$ Emerg Med, 2012;5(1):28.

25. Agrawal A, Gode D, Kakani A, Nagrale M, Quazi SZ, Gaidhane A, Shaikh P. Resource utilization in the management of traumatic brain injury patients in a critical care unit: An audit from rural setup of a developing country. Int J Crit Illn Inj Sci, 2011;1(2):110-3.

26. Cassidy JD, Carroll LJ, Peloso PM, Borg J, von Holst H, Holm L, Kraus J, Coronado VG. Incidence, risk factors and prevention of mild traumatic brain injury: results of the WHO Collaborating Centre Task Force on Mild Traumatic Brain Injury. $J$ Rehabil Med, 2004;(43 Suppl):28-60.

27. Wani AA, Ramzan AU, Dar TI, Malik NK, Khan AQ, Wani MA, Alam S, Nizami FA. Management dilemma in penetrating head injuries in comatose patients: Scenario in underdeveloped countries. Surg Neurol Int, 2012;3:89.

28. Razzak JA, Sasser S, Kellermann AL. Injury prevention and other international public health initiatives. Emerg Med Clin North Am, 2005;23(1):85-98.

29. Eckersley W, Salmon R, Gebru M, Khat. Driver impairment and road traffic injuries: a 
view from Ethiopia. Bull World Health Organ, 2010;88(3): 235-6.

30. Wagner ATA. Trauma in Afrika - das vergessene Problem. MMW-Fortschr.Med., 2006;148(1):9-12.
31. Sasser SVM, Kellermann A, Lormand JD. Prehospital trauma care systems, 2005, World Health Organization: Geneva. 